\title{
Defumação da Tilápia do Nilo (Oreochromis niloticus) Inteira Eviscerada e Filé: Aspectos Referentes às Características Organolépticas, Composição Centesimal e Perdas Ocor- ridas no Processamento
}

\section{Maria Luiza Rodrigues de Souza ${ }^{1}$, Ana Eliza Baccarin ${ }^{2}$, Elisabete Maria Macedo Viegas ${ }^{3}$, Sérgio do Nascimento Kronka ${ }^{4}$}

\begin{abstract}
RESUMO - O objetivo do experimento foi avaliar o efeito da defumação da tilápia do Nilo (Oreochromis niloticus) inteira eviscerada e filé sobre as características organolépticas (aparência, aroma, cor, sabor, textura, teor de sal e aceitação geral), a porcentagem de perda de peso (PP) e composição centesimal. Foram comparados FP1 (peixe inteiro eviscerado, 5 horas de fumaça) e FP2 (filé, 4 horas de fumaça). Os peixes foram descamados, eviscerados, para obtenção de FP1 ou filetados por uma única pessoa, para obtenção de FP2, e então submetidos à salmouragem úmida (30\%) e à defumação. O rendimento médio para FP1 e FP2 foi de 63,98 e 27,11\%, respectivamente. O valor médio para porcentagem de perda de peso ocorrida na defumação para o filé (31,33\%) foi superior ao peixe inteiro (27,04\%). A análise sensorial revelou que o peixe inteiro teve melhor aceitação quanto ao sabor e teor de sal e não diferiu do filé quanto ao aroma, cor e textura. O processo de defumação reduziu o conteúdo de umidade e proporcionou aumento nos teores de proteína bruta, lipídios e cinzas. As perdas foram maiores para o filé, que apresentou maior teor de proteína bruta e menor teor de lipídios comparado ao peixe inteiro. Verificou-se também que o sabor do filé pode ser melhorado em função de uma correção na salmouragem.
\end{abstract}

Palavras-chave: características organolépticas, defumação, Oreochromis niloticus, processamento

\section{Smoking Process of Whole Eviscerated and Fillet of Nile Tilapia (Oreochromis niloticus): Organoleptic Characteristics, Proximate Composition and Losses During Processing}

\begin{abstract}
The objective of the experiment was to evaluate the smoking process effect of whole eviscerated and fillet of Nile tilapia on the organoleptic characteristics (appearance, aroma, color, flavor, texture, salt content and general acceptance), percent weight loss (PP) and proximate composition. FP1 (whole eviscerated fish, 5 hour smoking) and FP2 (fillet, 4 hour smoking) were compared. Scaled, eviscerated fish, FP1 and fillets cut by only one person, FP2 were submitted to brine (30\%) and smoking process. Average yield for FP1 and FP2 was $63.98 \%$ and $27.11 \%$, respectively. Average loss weight during smoking for fillet (31.33\%) was higher, when compared to whole fish (27.04\%). Sensorial analysis showed that whole fish was more accepted, regarding flavor and salt content; however, aroma, color and texture were not different between whole fish and fillet. Smoking process reduced moisture and increased crude protein, lipid and ash contents. Losses were higher for fillet, which presented higher crude protein and lower lipid contents compared to whole fish. It was also verified that fillet flavor can be improved by correcting the brine step.
\end{abstract}

Key Words: characteristic organoleptic, Oreochromis niloticus, processing, smoking

\section{Introdução}

A criação de tilápias encontra-se amplamente distribuída no mundo inteiro, podendo atingir uma produção mundial de $1.500 .000 \mathrm{t}$ em 2010 , segundo Fitzsimmons (2000). Por serem consideradas espécies de grande importância para a aqüicultura mundial, as tilápias são freqüentemente indicadas para a criação intensiva. A tilápia do Nilo (Oreochromis niloticus) destaca-se como uma das mais importantes, devido à sua alta taxa de crescimento, adaptabilidade em diversas condições e criação e boa aceitação pelo consumidor (Kubitza, 2000), principalmente pela excelente textura e pelo sabor de sua carne e ausência

\footnotetext{
${ }^{1}$ Profa. Dra. do Depto de Zootecnia - Universidade Estadual de Maringá. Av. Colombo 5790, CEP: 87020-900, Maringá - PR, Brasil. E.mail:mlrsouza@uem.br

2 Pós-Doutoranda do CAUNESP/UNESP - Jaboticabal. CAPES. Via de Acesso Prof. Paulo Donato Castellane, s/n. CEP: 14884-900, Jaboticabal - SP, Brasil. E.mail: anaeliza@caunesp.unesp.br

${ }^{3}$ Prof $^{a}$ Dr $^{\text {a }}$ do Depto de Zootecnia/FZEA-USP e CAUNESP/Jaboticabal. Av. Duque de Caxias Norte, 225, CEP: 13635-900, Pirassununga - SP, Brasil. E.mail: emviegas@usp.br

4 Universidade do Oeste Paulista - UNOESTE - Presidente Prudente. Pesquisador do CNPq. Rod. Raposo Tavares Km 572, s/n. CEP: 19067-175, Presidente Prudente - SP, Brasil. E.mail: kronka@agro.unoeste.br
} 
de espinhos intramusculares (Lima et al., 2000).

O consumo de peixes ainda é baixo no Brasil, em torno de $6 \mathrm{~kg} /$ habitante/ano (Macedo-Viegas et al., 2000). Uma das maneiras de se reverter este quadro seria o uso de mecanismos que estimulem as diferentes formas de apresentação dos pescados, uma vez que o consumidor busca alimentos de fácil e rápido preparo.

A defumação, embora seja uma antiga técnica de conservação, tem sido utilizada atualmente como um artifício para melhorar a qualidade dos pescados, uma vez que provoca mudanças nos atributos sensoriais como odor, sabor, coloração e textura (Sigurgisladottir et al., 2000). O êxito na preparação de defumados depende da aplicação da fumaça e da combinação de fatores físicos e químicos, sendo necessário um controle rigoroso de cada uma das etapas da defumação.

A forma de apresentação do produto final ao consumidor, seja inteiro eviscerado, filé com ou sem pele, em postas, tronco limpo sem cabeça ou outros, pode interferir na aceitabilidade do mesmo. Segundo Miler \& Sikorski (1994), dependendo do tamanho, peculiaridades do peixe, bem como características que o produto final deve exibir, praticam-se diferentes técnicas de limpeza e cortes.

A produção mundial de peixes defumados nas últimas décadas tem sido muito baixa; do total capturado, apenas 0,80\% em 1977 foi destinado à defumação (Aminullah-Bruiyan et al., 1986). Em 1999, apenas 2\% da produção mundial de pescado era destinado à defumação, sendo que, no Brasil, a produção desse tipo de produto, é muito restrita, principalmente para peixes de água doce (Nunes, 1999).

Os métodos ou tipos de defumação variam de acordo com os produtos desejados, tipos de defumadores, madeiras utilizadas, entre outros. No entanto, para a operação de defumação de pescado, existem três fases distintas e imprescindíveis à boa qualidade do produto: a salmouragem, a secagem e a defumação propriamente dita. Tradicionalmente podem-se utilizar duas formas - a defumação a quente ou a frio, alterando-se a temperatura da câmara de defumação (defumador) utilizada. Segundo Miler \& Sikorski (1994), a temperatura não deve exceder a $30^{\circ} \mathrm{C}$ durante a defumação a frio e não deve ser inferior a $60^{\circ} \mathrm{C}$ para defumação a quente. A diferença da defumação a frio é que as proteínas do pescado se tornam comestíveis, devido à maturação enzimática, ao passo que, na defumação a quente, isto ocorre em virtude da desnaturação das proteínas pelo efeito do calor (Miler \& Sikorski, 1994). Como conseqüência, os produtos obtidos nos dois procedimentos diferem em suas características organolépticas e vida útil.

A principal função da defumação a quente é proporcionar aroma, sabor e cor característicos, com melhores qualidades sensoriais (Rhee \& Bratzler, 1970; Simko, 1991; Morais, 1994). A defumação a frio é muito utilizada para introduzir características com funções preservativas devido ao maior tempo de exposição do pescado à fumaça quando comparada à defumação a quente. Também há outras formas como a defumação eletrostática e a defumação líquida, esta última muito utilizada atualmente.

O objetivo deste trabalho foi avaliar o efeito da defumação em duas formas de apresentação (inteiro eviscerado e filé) de tilápia do Nilo (Oreochromis niloticus) sobre as características organolépticas (aparência, aroma, cor do produto final e sabor, textura, teor de sal e aceitação geral da porção), composição centesimal e perdas ocorridas durante o processo de defumação.

\section{Material e Métodos}

O experimento foi conduzido no Centro de Aqüicultura, UNESP (CAUNESP, Jaboticabal, SP) de agosto a outubro de 2000. O processo de defumação foi realizado em um defumador de capacidade de $100 \mathrm{~kg}$.

\section{Peixe e processo de filetagem}

Foram utilizados 40 tilápias do Nilo (Oreochromis niloticus), capturadas de tanques instalados no Centro de Aqüicultura/ UNESP de Jaboticabal. Os peixes foram submetidos a um choque térmico (abate) em caixas isotérmicas com gelo e água (1:1) e separados em dois lotes de vinte $(445,00 \pm 103,28 \mathrm{~g})$ para a defumação dos peixes inteiros e eviscerados (retiradas as vísceras, brânquias e escamas) e vinte (435,04 $\pm 95,39 \mathrm{~g})$ para a defumação dos filés com pele. $O$ processo de filetagem foi conduzido por uma única pessoa para evitar-se o efeito do filetador nos cálculos de rendimento.

\section{Procedimento experimental}

O procedimento de defumação utilizado consta no fluxograma da Figura 1.

Após a pesagem, os peixes foram lavados, para remoção de muco da superfície da pele e impurezas, 
escamados, eviscerados, removidas as brânquias e novamente lavados, para eliminação do sangue proveniente do abate. Em seguida, os peixes foram distribuídos aleatoriamente entre os dois tratamentos. Os peixes inteiros eviscerados foram pesados e identificados com uma placa metálica e os demais, submetidos ao processo de filetagem. Cada filé foi pesado e identificado da mesma maneira logo após a filetagem.

Os peixes inteiros eviscerados e filés foram imersos em uma solução de salmoura a 30\%, na proporção de 2:1 (volume da salmoura/peso), por 45 minutos. Após a

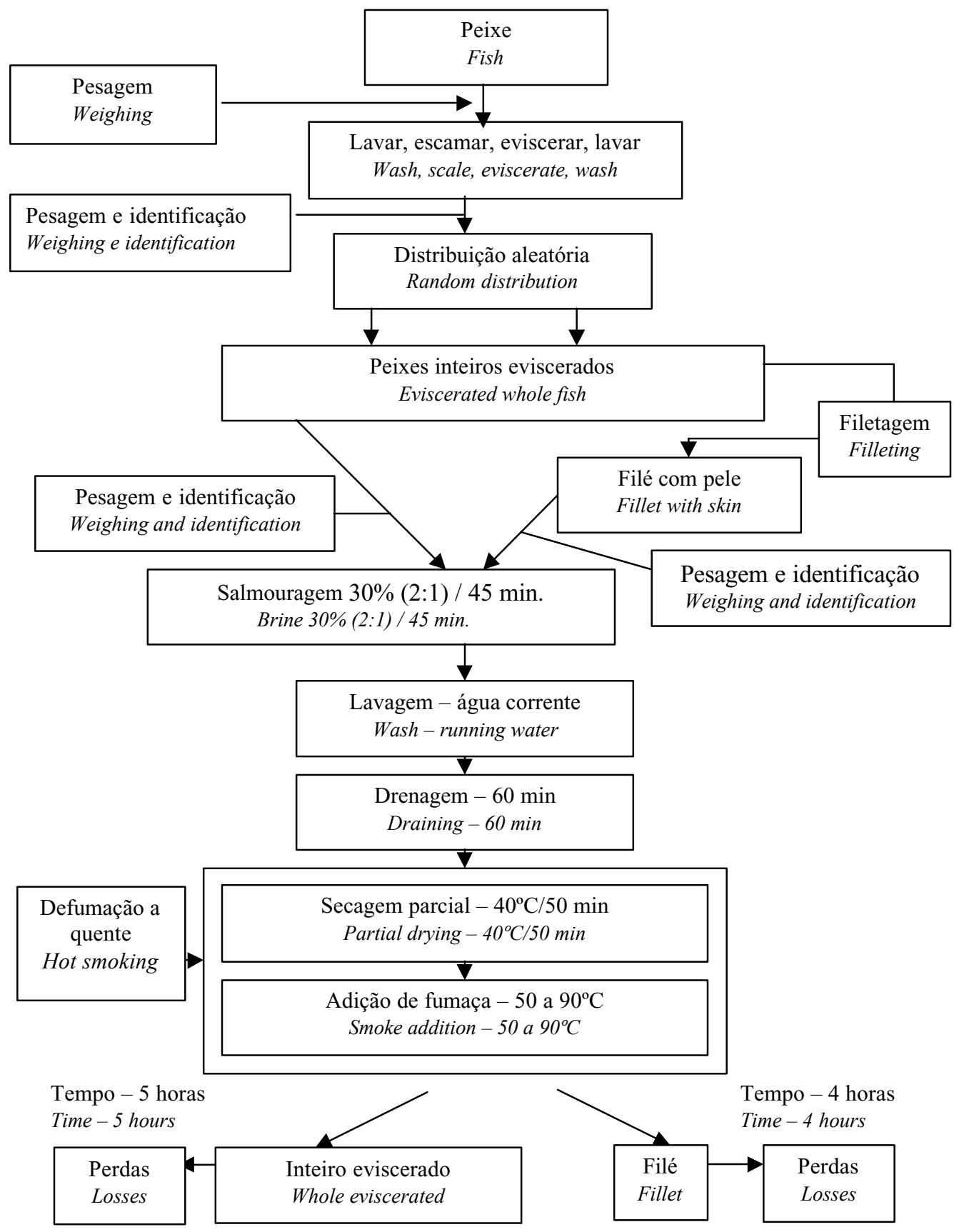

Figura 1 - Fluxograma do método de defumação a quente, utilizado para tilápia inteira eviscerada e filé. Figure 1 - Flowchart of hot smoking process of Nile tilapia, whole eviscerated fish and fillet. 
salga, foram lavados em água corrente para eliminar o excesso de sal da superfície para evitar a formação de cristais após a defumação e drenados por uma hora, para perda da água superficial. Então, os peixes e filés foram colocados dentro da câmara de defumação, para secagem parcial (aquecido a gás) a uma temperatura de $40^{\circ} \mathrm{C}$, por 50 minutos.

A temperatura do processamento iniciou-se com $50^{\circ} \mathrm{C}$ e atingiu $90^{\circ} \mathrm{C}$ no máximo, após a adição da fumaça, com aumento de $10^{\circ} \mathrm{C}$ a cada hora. Os peixes inteiros eviscerados receberam fumaça por um período de 5 horas, enquanto os filés, 4 horas. O produto defumado foi submetido a uma limpeza, para remover fuligens aderidas à superfície, embalado e estocado sob refrigeração $\left(5^{\circ} \mathrm{C}\right)$ até o momento da realização da análise sensorial.

O combustível utilizado para produzir a fumaça foi a serragem de eucalipto rosa e, para manutenção da temperatura, o gás de cozinha.

\section{Análise sensorial}

Subamostras de tilápias defumadas ( $\pm 5 \mathrm{~g}$ ) foram analisadas por um painel de 30 provadores não terinados, que avaliou os produtos defumados, 24 horas após a defumação. Foram retiradas amostras de $5 \mathrm{~g}$ aproximadamente, embaladas em papel alumínio, aquecidas em forno convencional (a gás) e oferecidas aos provadores não treinados. Foram avaliados os atributos de sabor, textura, teor de sal e aceitação geral das porções dos peixes Os produtos finais (peixes inteiros eviscerados e filés) também foram avaliados quanto à aparência, cor, aroma e aceitação geral. Para tanto, foi utilizada uma ficha com escala hedônica de 9 pontos com os extremos 1 (desgostei muitíssimo) e 9 (gostei muitíssimo).

\section{Análise de composição centesimal}

Seis amostras de cada tratamento, bem como amostras de peixe in natura foram estocadas a $-18^{\circ} \mathrm{C}$, logo após a defumação, para a análise de composição centesimal. No momento da realização das análises, as amostras descongeladas foram moídas em multiprocessador e desse homogeneizado foi removida uma alíquota para a determinação da composição de matéria seca (estufa a $105^{\circ} \mathrm{C}$ por $16 \mathrm{~h}$ ), extrato etéreo (extrator de Sohxlet), proteína bruta (Microkjeldahl) e cinzas (forno mufla a $600^{\circ} \mathrm{C}$ por 3 horas), de acordo com os métodos oficiais da AOAC (1995).

\section{Perdas ocorridas durante o processamento}

As perdas foram determinadas no processo de abate e filetagem e ao longo do processo de defumação, envolvendo 6 tempos em comum para os dois tratamentos analisados $(\mathrm{T} 1=$ drenagem; $\mathrm{T} 2=$ secagem parcial; T3, T4, T5 e T6 = adição de fumaça na $1^{\mathrm{a}}$ a $4^{\mathrm{a}}$ hora de defumação). Para o defumado inteiro eviscerado adicionou-se mais uma hora de fumaça (T7) para complementação do processo (apresentar cor e cozimento suficiente). Os rendimentos do peixe inteiro eviscerado e filé foram determinados para as formas in natura e produto defumado.

\section{Análise estatística}

As variáveis foram analisadas de acordo com o modelo matemático:

$$
\mathrm{Y}_{\mathrm{ij}}=\mu+\mathrm{Fi}+\mathrm{e}_{\mathrm{ij}}
$$

em que $Y_{i j}=$ observação referente ao peixe $j$, no processo de defumação i; $\mu=$ constante comum a todas as observações; $F_{i}=$ efeito da forma de apresentação do produto final $\mathrm{i},(\mathrm{i}=1 ; 2) ; \mathrm{e}_{\mathrm{ij}}=$ erro aleatório associado a cada observação ij.

Para análise da composição centesimal, o modelo matemático foi o mesmo, com acréscimo do tratamento testemunha (inteiro eviscerado e filé in natura). Quanto à análise sensorial, foi acrescido o efeito de bloco (provador).

Os resultados da análise sensorial, determinação da composição centesimal e perdas no processamento foram submetidos à análise de variância, e as médias, comparadas pelo teste de Tukey, a $5 \%$ de probabilidade (Banzatto \& Kronka, 1995).

\section{Resultados e Discussão}

\section{Análise sensorial}

Os resultados das características organolépticas da tilápia defumada, na forma de apresentação em filé e inteira eviscerada, constam da Tabela 1. Para os dados transformados $(\sqrt{ } \mathrm{x}+0,5)$, os provadores não notaram diferença $(\mathrm{P}<0,05)$ entre os tratamentos para os atributos de aroma, cor e textura. Todavia, houve diferença significativa $(\mathrm{P}<0,01)$ para aparência, sabor, teor de sal e aceitação geral.

Os resultados foram significativamente $(\mathrm{P}<0,01)$ superiores para o filé quanto a sua aparência e aceitação geral em relação ao peixe inteiro. No entanto, quando os provadores degustaram amostras dos produtos, o resultado foi diferente, ou seja, o sabor, o teor de sal e a aceitação geral foram superiores $(\mathrm{P}<0,01)$ para a tilápia defumada na forma inteira eviscerada (Tabela 1).

Pode-se inferir que o consumidor ao comprar o 
produto, em princípio, observa a sua aparência, cor, aroma, ou seja, suas características mais atrativas. Neste experimento, o peixe defumado na forma de filé foi preferido pelos provadores. Todavia, como se observa na Tabela 1, o consumidor considerou que o teor de sal não era adequado para o filé. Desse modo, a utilização da mesma proporção de sal e mesmo tempo para a salmouragem nos dois tratamentos não pode ser utilizada, pois o filé apresentou maior teor de sal, afetando conseqüentemente os resultados de sabor, que por sua vez foi pior para o filé.

Souza et al. (2000) relataram que filés de matrinxã (Brycon cephalus) submetidos à defumação a quente $\left(60\right.$ a $80^{\circ} \mathrm{C}$, por 5 horas) receberam valores médios transformados $(\sqrt{ } \mathrm{x}+0,5)$ de 2,68 para a aparência do filé, portanto inferiores ao filé de tilápia defumada (50 a $90^{\circ} \mathrm{C}$, por 4 horas) deste experimento. Entretanto, as notas atribuídas para o filé defumado, quanto às características de aroma, cor, sabor, textura e teor de sal, foram semelhantes aos relatados por Souza et al. (2000). Em relação à aceitação do filé de tilápia, o valor foi inferior ao relatado pelos mesmos autores, para a matrinxã (Tabela 1).

Composição centesimal

Os resultados de composição centesimal da matéria-prima in natura e do produto final, tanto dos peixes inteiros eviscerados como dos filés, encontram-se na Tabela 2.

Alguns fatores influenciam a composição centesimal do pescado, como alimentação, idade, peso, variação sazonal, fase fisiológica (Shearer, 1994), bem como as diferentes regiões do corpo (Contreras-Guzmán, 1994). Portanto, para evitar qualquer fator que pudesse influenciar na análise, foram utilizados peixes de mesma categoria de peso, capturados do mesmo viveiro e recebendo a mesma dieta. Além desses fatores, ainda existe aquele relacionado com o tipo de processamento do pescado, como exemplo o processo de defumação que interfere na composição centesimal (Gonçalves \& Prentice-Hernández, 1998; Sigurgisladottir et al., 2000; Ribeiro, 2000).

De acordo com Aminullah-Bruiyan et al. (1986), raramente são relatados os nutrientes do produto defumado comparado ao in natura; no entanto, Gilbert \& Knowels (1975) relatam que diferenças ocorrem com a defumação, resultando em alterações na qualidade nutricional do produto final.

Houve diferença na composição centesimal $(\mathrm{P}<0,01)$ dos peixes inteiros eviscerados e filés in natura comparados aos defumados (Tabela 2). $\mathrm{O}$ processo de defumação alterou as porcentagens dos

Tabela 1 - Valores médios das notas atribuídas pelos provadores às características organolépticas das duas formas de apresentação da tilápia do Nilo (Oreochromis niloticus) defumada

Table 1 - Mean values attributed by the test panel to organoleptic characteristics of smoked Nile tilapia (Oreochromis niloticus), whole eviscerated fish and fillet

\begin{tabular}{|c|c|c|c|c|c|c|c|c|}
\hline \multirow[b]{3}{*}{$\begin{array}{l}\text { Formas de } \\
\text { apresentação } \\
\text { Presentation }\end{array}$} & \multicolumn{8}{|c|}{$\begin{array}{c}\text { Características organolépticas }{ }^{1} \\
\text { Organoleptic characteristics }^{1}\end{array}$} \\
\hline & \multicolumn{4}{|c|}{$\begin{array}{l}\text { Produto final } \\
\text { Final product }\end{array}$} & \multicolumn{4}{|c|}{$\begin{array}{l}\text { Porção } \\
\text { Portion }\end{array}$} \\
\hline & $\begin{array}{l}\text { Aparência } \\
\text { Appearance }\end{array}$ & $\begin{array}{l}\text { Aroma } \\
\text { Aroma }\end{array}$ & $\begin{array}{l}\text { Cor } \\
\text { Color }\end{array}$ & $\begin{array}{l}\text { Aceitação } \\
\text { geral } \\
\text { General } \\
\text { acceptance }\end{array}$ & $\begin{array}{l}\text { Sabor } \\
\text { Flavor }\end{array}$ & $\begin{array}{l}\text { Textura } \\
\text { Texture }\end{array}$ & $\begin{array}{c}\text { Teor de } \\
\text { sal } \\
\text { Salt } \\
\text { content }\end{array}$ & $\begin{array}{l}\text { Aceitação } \\
\text { geral } \\
\text { General } \\
\text { acceptance }\end{array}$ \\
\hline Inteiro & $2,54^{\mathrm{B}}$ & $2,77^{\mathrm{A}}$ & $2,67^{\mathrm{A}}$ & $2,57^{\mathrm{B}}$ & $2,98^{\mathrm{A}}$ & $2,90^{\mathrm{A}}$ & $2,95^{\mathrm{A}}$ & $2,88^{\mathrm{A}}$ \\
\hline $\begin{array}{l}\text { Whole fish } \\
\text { Filé } \\
\text { Fillet }\end{array}$ & $2,73^{\mathrm{A}}$ & $2,78^{\mathrm{A}}$ & $2,72^{\mathrm{A}}$ & $2,67^{\mathrm{A}}$ & $2,88^{\mathrm{B}}$ & $2,83^{\mathrm{A}}$ & $2,81^{\mathrm{B}}$ & $2,76^{\mathrm{B}}$ \\
\hline $\begin{array}{l}\text { Teste } \mathrm{F} \\
\text { F test }\end{array}$ & $10,31^{* *}$ & $1,44^{\mathrm{NS}}$ & $1,41^{\mathrm{NS}}$ & $4,39^{*}$ & $7,22 * *$ & $1,54^{\mathrm{NS}}$ & $8,21 * *$ & $8,15^{* *}$ \\
\hline CV (\%) & 8,50 & 2,75 & 6,61 & 6,88 & 4,56 & 7,05 & 6,41 & 6,02 \\
\hline
\end{tabular}

1 Valores transformados para $\sqrt{ } \mathrm{x}+0,5$

1 Values transformed by $\sqrt{ } x+0.5$

ns - não significativo $(P>0,05) ;{ }^{*}$ significativo $(P<0,05) ;{ }^{* *}$ significativo $(P<0,01)$.

$n s$ - not significant $(P>.05)$; * significant $(P<.05)$; ${ }^{* *}$ significant $(P<.01)$.

R. Bras. Zootec., v.33, n.1, p.27-36, 2004 
Tabela 2 - Valores médios para composição centesimal do peixe inteiro eviscerado e do filé da tilápia do Nilo, in natura e defumado, e valores de $\mathrm{F}$ e coeficiente de variação (CV)

Table 2 - Average proximate composition of whole eviscerated fish and fillet of Nile tilapia, in natura and smoked, $F$ values and coefficient of variation (CV)

\begin{tabular}{|c|c|c|c|c|}
\hline \multirow[b]{2}{*}{$\begin{array}{l}\text { Tratamentos } \\
\text { Treatments }\end{array}$} & \multicolumn{4}{|c|}{$\begin{array}{l}\text { Composição centesimal } \\
\text { Proximate composition }\end{array}$} \\
\hline & $\begin{array}{l}\text { Umidade } \\
\text { Moisture } \\
(\%)\end{array}$ & $\begin{array}{c}\text { Proteína bruta } \\
\text { Crude protein } \\
(\%)\end{array}$ & $\begin{array}{l}\text { Lipídios } \\
\text { Lipids } \\
(\%)\end{array}$ & $\begin{array}{c}\text { Cinzas } \\
\text { Ash } \\
(\%)\end{array}$ \\
\hline $\begin{array}{l}\text { Inteiro in natura } \\
\text { Whole in natura }\end{array}$ & $70,84^{\mathrm{B} 1 /}$ & $19,20^{\mathrm{C}}$ & $8,06^{\mathrm{B}}$ & $3,41^{\mathrm{C}}$ \\
\hline $\begin{array}{l}\text { Inteiro defumado } \\
\text { Smoked whole }\end{array}$ & $57,18^{\mathrm{D}}$ & $25,27^{\mathrm{B}}$ & $11,31^{\mathrm{A}}$ & $7,30^{\mathrm{A}}$ \\
\hline $\begin{array}{l}\text { Filé in natura } \\
\text { Fillet in natura }\end{array}$ & $77,91^{\mathrm{A}}$ & $25,65^{\mathrm{B}}$ & $2,55^{\mathrm{D}}$ & $1,04^{\mathrm{D}}$ \\
\hline $\begin{array}{l}\text { Filé defumado } \\
\text { Smoked fillet }\end{array}$ & $63,00^{\mathrm{C}}$ & $33,04^{\mathrm{A}}$ & $4,47^{\mathrm{C}}$ & $5,13^{\mathrm{B}}$ \\
\hline $\begin{array}{l}\text { Teste F } \\
\text { F test }\end{array}$ & $313,61 * *$ & $80,73 * *$ & $95,81 * *$ & $89,72 * *$ \\
\hline $\mathrm{CV}$ & 1,86 & 5,99 & 14,73 & 16,26 \\
\hline
\end{tabular}

componentes da matéria-prima in natura, pois, ao reduzir a umidade de 70,84 para $57,18 \%$ e de 77,91 para $63,00 \%$, respectivamente, para peixe inteiro eviscerado e filé, houve aumento no conteúdo de proteína de 6,07 e 7,39\%; de lipídios de 3,25 e 1,92\% e de cinzas de 3,89 e $4,09 \%$, respectivamente, para as formas de apresentação do produto, conforme pode ser observado na Tabela 2.

De acordo com Gonçalves \& Prentice-Hernández (1998) e Ribeiro (2000), em pescados defumados, o conteúdo de proteína e lipídios é mais elevado que no pescado in natura, principalmente devido à perda excessiva de umidade, decorrente do processo de desidratação e lixiviação de lipídios do músculo que ocorre durante a defumação (Sigurgisladottir et al., 2000).

Quanto à forma de apresentação do produto, no filé tanto in natura quanto defumado, as porcentagens de umidade e proteína foram significativamente $(\mathrm{P}<0,01)$ superiores comparadas ao peixe inteiro eviscerado, enquanto as porcentagens de lipídios e cinzas foram inferiores para o filé (Tabela 2). Era esperado que o teor de proteína no filé fosse superior ao inteiro eviscerado, devido à maior relação de massa muscular presente no filé em comparação ao inteiro eviscerado. Da mesma forma, os lipídios e cinzas são superiores no peixe inteiro eviscerado, devido à elevada quantidade de gordura existente em determinadas regiões do corpo do peixe, como na região abdominal, e para cinzas, pela presença de todo o esqueleto ósseo.

De acordo com Ogawa (1999), o músculo do pescado contém de 60 a $85 \%$ de umidade e os valores médios observados neste trabalho com a tilápia do Nilo, situam-se dentro dessa faixa, sendo que na forma de inteiro eviscerado defumado encontra-se próximo ao limite inferior da faixa citada pelo autor, embora se trate de peixes inteiros e defumados e não somente da parte muscular e in natura.

Em relação ao peixe in natura, Clement \& Lovell (1994) relataram valores de 75,3\% de umidade para filé de tilápia do Nilo com peso médio de $585 \mathrm{~g}$, valor inferior ao obtido neste trabalho, para filé in natura. Os mesmo autores observaram valores de 20,$3 ; 5,7$ e 2,3\% para proteína, lipídios e cinzas, respectivamente, para filés in natura de tilápia do Nilo. Todavia, neste trabalho, o valor de proteína $(25,65 \%)$ foi superior ao citado pelos mesmos autores, 
enquanto lipídios $(2,55 \%)$ e cinzas $(1,04 \%)$, inferiores.

Os acréscimos de lipídios, observados nos defumados (filé e inteiro eviscerado), são decorrentes da desidratação ocorrida em função do processamento de defumação. $O$ teor de gordura é muito importante para o processo de defumação. Peixes considerados gordos (acima de 10\% de lipídios) são os mais indicados, principalmente devido ao fato de que esse teor de gordura da musculatura interfere no aroma e sabor do defumado (Nunes, 1999). Geromel \& Forster (1982) afirmam que a gordura do pescado atua como absorvedor das substâncias aromáticas presentes na fumaça. Nesse sentido, a tilápia não poderia ser uma espécie muito indicada para a defumação, por ser considerado um peixe magro. Entretanto, realizando a análise sensorial, notou-se que este produto teve boa aceitação pelos provadores (Tabela 1).

$\mathrm{O}$ aumento dos teores de cinzas no peixe inteiro in natura, de 3,41\% para $7,30 \%$ e de $1,04 \%$ no filé in natura para $5,13 \%$ no defumado, ocorreu devido à desidratação e à absorção de cloreto de sódio no músculo, durante o processo da salmouragem para a defumação, sendo que o mesmo observado por Gonçalves \& Prentice-Hernández (1998).

\section{Perdas ocorridas durante o processamento}

$\mathrm{Na}$ Figura 2 consta um fluxograma demonstrando as perdas ocorridas no processamento da tilápia do Nilo defumada.

O tipo de processamento da tilápia do Nilo (inteiro eviscerado e filé) proporcionou diferentes perdas de peso, quanto ao abate e/ou filetagem e no próprio processo de defumação. No total, o peixe inteiro perdeu $36,67 \%$ de peso, enquanto o filé, $72,89 \%$, com relação ao peso inicial (Figura 2). O peixe inteiro perdeu mais peso na defumação (22,99\%), quando comparado ao filé (12,09\%). Beraquet \& Mori (1984) relatam perdas de peso na defumação a quente de 20 a $27,5 \%$ para cavalinha espalmada (Scomber japonicus), enquanto as perdas totais em relação ao peso da cavalinha fresca foram de 45,5 a $47,8 \%$.

$\mathrm{O}$ rendimento do peixe inteiro defumado foi de $63,33 \%$, enquanto o rendimento de filé defumado foi $27,11 \%$ em relação ao peso corporal total do peixe (Figura 2). Todavia, desse percentual de rendimento de filé defumado, apenas é descontado um pequeno valor referente a pele do filé que não é comestível, pois ela se apresenta gelatinizada, devido à desnaturação das fibras colágenas presentes na derme da pele, enquanto no peixe inteiro estão incluídos a cabeça, nadadeiras, coluna vertebral, espinhas, assim como, a própria pele que recobre todo o produto defumado.

$\mathrm{Na}$ Tabela 3, constam as porcentagens de perdas de peso, em função dos tempos definidos no decorrer do processo de defumação, do peixe inteiro eviscerado e do filé da tilápia do Nilo.

Podem-se observar diferenças significativas de perdas de peso entre as formas de apresentação e entre os tempos da defumação, sendo que as perdas ocorridas nos filés $(31,33 \%)$, ao final do processo de

Tabela 3 - Médias das porcentagens de perdas de peso nos tempos de defumação do peixe inteiro eviscerado e do filé da tilápia do Nilo

Table 3 - Average percent weight losses during the smoking process of Nile tilapia, whole eviscerated fish and fillet

Tempos no processo de defumação

Lenght of smoking process

\begin{tabular}{|c|c|c|c|c|c|c|c|}
\hline \multirow{2}{*}{$\begin{array}{l}\text { Formas de } \\
\text { Processamento } \\
\text { Forms of } \\
\text { processing } \\
\end{array}$} & \multicolumn{2}{|c|}{$\begin{array}{cc}\text { Drenagem } & \text { Secagem } \\
\text { Draining } & \text { Drying } \\
\end{array}$} & \multicolumn{5}{|c|}{$\begin{array}{c}\text { Adição de fumaça } \\
\text { Smoke addition }\end{array}$} \\
\hline & $\mathrm{T}_{1}$ & $\mathrm{~T}_{2}$ & $\mathrm{~T}_{3}$ & $\mathrm{~T}_{4}$ & $\mathrm{~T}_{5}$ & $\mathrm{~T}_{6}$ & $\mathrm{~T}_{7}$ \\
\hline $\begin{array}{l}\mathrm{FP}_{1}=\text { Inteiro } \\
F P_{1}=\text { Whole fish }\end{array}$ & $4,03^{\mathrm{aA} 1}$ & $1,38^{\mathrm{cB}}$ & $2,50^{\mathrm{bB}}$ & $4,86^{\mathrm{aB}}$ & $4,63^{\mathrm{aB}}$ & $4,66^{\mathrm{aB}}$ & 4,98 \\
\hline $\begin{array}{l}\mathrm{FP}_{2}=\text { Filé } \\
F P_{2}=\text { Fillet }\end{array}$ & $2,07^{\mathrm{dB}}$ & $4,17^{\mathrm{cA}}$ & $4,77^{\mathrm{cA}}$ & $7,27^{\mathrm{aA}}$ & $7,04^{\mathrm{aA}}$ & $6,01^{\mathrm{bA}}$ & - \\
\hline
\end{tabular}

${ }^{1}$ Em cada linha (coluna), médias seguidas de mesma letra minúscula (maiúscula) não diferem entre si, pelo teste de Tukey $(\mathrm{P}>0,05)$. Teste $\mathrm{F}$ para Interação (Forma de apresentação x Períodos) $=42,50$ ** $\mathrm{CV}($ parcela $)=20,28 \%, \mathrm{CV}$ (subparcelas) $=21,33 \%$.

1 In each column, average followed by the same capital letter did not differ among themselves by Tukey test (P>.05). Test $F$ for interaction (Presentation $x$ Periods $)=42.50^{* *} \mathrm{CV}($ plot $)=20.28 \%, \mathrm{CV}($ split-plot $)=21.33 \%$. 
defumação (seis tempos), foram superiores $(\mathrm{P}<0,01)$ as do peixe inteiro eviscerado $(27,04 \%)$ defumado em sete tempos, em relação ao peso in natura nas duas formas de apresentação (Tabela 3; Figura 2).

Essas perdas de peso ocorridas, provavelmente, são devidas à desidratação (Tabela 2) que ocorre durante a defumação. Segundo Howgate (1979), citado por Sigurgisladottir et al. (2000), estas perdas podem variar de 10 a $25 \%$, dependendo do tipo de material in natura, características do produto final e parâmetros usados no processo, como o tempo e a temperatura.

Em cada tempo analisado, o filé apresentou maiores perdas $(\mathrm{P}<0,01)$, com exceção da primeira hora (T1), onde se observou menor valor em relação ao peixe inteiro eviscerado. Essa maior perda ocorrida
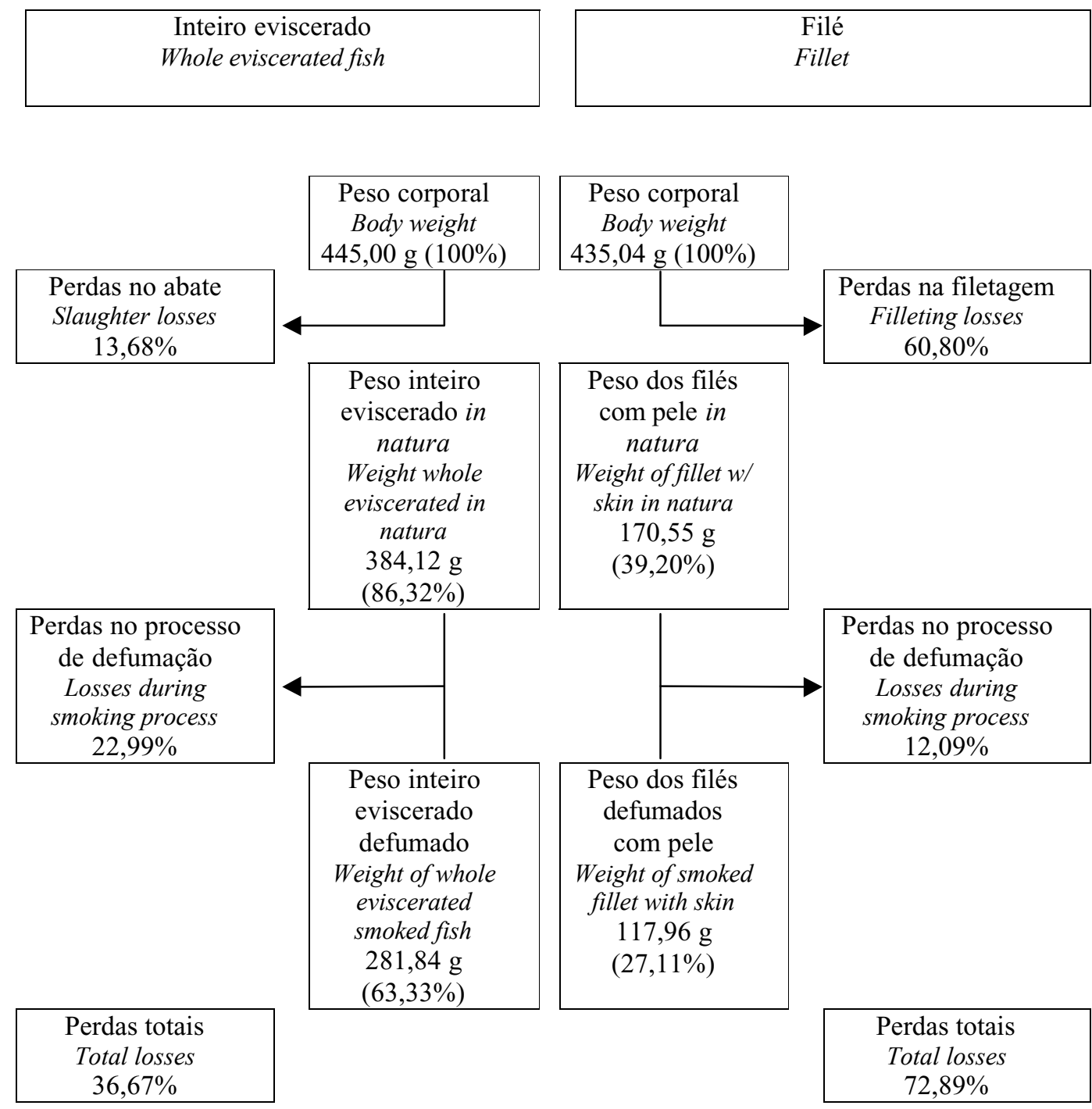

Figura 2 - Rendimentos e perdas (em relação ao peso corporal inicial) durante o processo de filetagem e de defumação a quente e a frio.

Figure 2 - Yields and losses (with respect to initial body weight) during the process of filleting and smoking, hot and cold. 
no peixe inteiro deve-se à maior proporção de água retida na superfície da pele, cavidade abdominal e branquial, após a lavagem para remoção do excesso de sal superficial decorrente da salmouragem. Nos tempos sucessivos da defumação, de acordo com RØra et al. (1998), a desidratação ocorreu em maior grau na superfície do filé, uma vez que a relação volume-superfície deste é maior favorecendo a maior perda de água.

Os teores de gorduras também podem influenciar as perdas durante o processo de defumação, ou seja, peixes com maior teor de gordura perdem menos água no processamento. R Øra et al. (1998) relatam que filés in natura de salmão do Atlântico com $17,40 \%$ de lipídios apresentaram perdas de peso de $8,1 \%$, quando defumados, enquanto as perdas de peso, no processo de defumação, no presente estudo, foram de $31,33 \%$ para os filés in natura de tilápia do Nilo com níveis de $2,5 \%$ de lipídios. Portanto, a diminuição das perdas durante a defumação pode ser explicada pela menor desidratação em peixes gordurosos, comparados aos magros (Sigurgisladottir et al., 2000).

\section{Conclusões}

O processo de defumação da tilápia do Nilo proporcionou diferentes perdas de peso nos produtos finais defumados, sendo maior nos filés que nos peixes inteiros apenas eviscerados. Com relação aos atributos sensoriais, o filé defumado teve melhor aceitação geral, principalmente quanto à aparência, embora a apresentação do peixe inteiro defumado tenha tido maior aceitação quanto ao sabor e teor de sal.

Com o processo de defumação, houve alteração na composição centesimal, ocorrendo perdas de umidade e, conseqüentemente, aumento na concentração dos teores de proteína bruta, lipídios e cinzas. O filé apresentou teor de lipídios inferior ao peixe inteiro defumado.

\section{Agradecimento}

À CAPES, pelo auxílio da bolsa de PICDt concedida ao primeiro autor. Ao Prof. Dr. Dalton Carneiro, pelo uso do Laboratório de Nutrição dos Organismos Aquáticos para realização das análises de composição centesimal. A todos os participantes do painel sensorial.

\section{Literatura Citada}

AMINULLAH BHUIYAN, A.K.M.; RATNAYAKE, W.M.N.; ACKMAN, R.G. Effect of smoking on the proximate composition of Atlantic mackerel (Scomber scombrus). Journal of Food Science, v.51, n.2, p.327-329, 1986.

ASSOCIATION OF OFFICIAL ANALYTICAL CHEMISTS AOAC. Official methods of analysis of the association of official analytical chemists. Arlington: 1995. v.2, p.1-30.

BANZATTO, D.A.; KRONKA, S.N. Experimentação agrícola. 3.ed. Jaboticabal: FUNEP, 1995. 247p.

BERAQUET, N.J.; MORI, E.E.M. Influência de diferentes métodos de defumação na aceitabilidade de cavalinha Scomber japonicus Houtt defumada. Coletânia do ITAL, v.14, p.1-25, 1984.

CLEMENT, S.; LOVELL, R.T. Comparison of culture Nile tilapia (Oreochromis niloticus) and channel catfish (Ictalurus punctatus). Aquaculture, v.119, p.299-310, 1994.

CONTRERAS-GUZMÁN, E.S. Bioquímica de pescados e derivados. Jaboticabal: FUNEP, 1994. 409p.

FITZSIMMONS, K. Tilapia: the most important aquaculture species of the $21^{\text {st }}$ century. In: INTERNACIONAL SYMPOSIUM ON TILAPIA AQUACULTURE, 50., 2000, Rio de Janeiro. Proceedings... Rio de Janeiro: 2000. V.1, p.3-8.

GEROMEL, E.J.; FORSTER, R.J. Princípios fundamentais em tecnologia do pescado. São Paulo: Secretaria da Indústria e Comércio, Ciência e Tecnologia, n. 11, 1982. 127p. (Série Tecnologia Agroindustrial).

GILBERT, J.; KNOWELS, M.E. The chemistry of smoked foods: a review. Journal Food Technology, v.10, p.245-261, 1975.

GONÇALVES, A.A.; PRENTICE-HERNÁNDEZ, C. Fumaça líquida: uma tecnologia para defumar pescado. Boletim SBCTA, v.32, n.2, p.189-199, 1998.

KUBITZA, F. Tilápia: tecnologia e planejamento na produção comercial. Jundiaí: Acqua \& Imagem, 2000. 289p.

LIMA, M.B.S; PADUA, D.M.C.; SILVA, P.C. et al. Farelo de milheto (Pennisetum americanum) em substituição ao milho moído (Zea mays) em dietas para tilápia Oreochromis niloticus. In: INTERNACIONAL SYMPOSIUM ON TILAPIA AQUACUlTURE, 55., 2000, Rio de Janeiro. Proceedings... Rio de Janeiro, 2000. v.1, p.120-124.

MACEDO-VIEGAS, E.M.; SOUZA, M.L.R; BACCARIN, A.E. et al. Aspectos mercadológicos de pescados e derivados em algumas cidades das regiões sul e sudeste do Brasil.Infopesca Internacional, v.6, p.13-22, 2000.

MILER, K.B.M.; SIKORSKI, Z.E. Ahumado. In: SIKORSKI, Z. E. (Ed.) Tecnologia de los productos del mar: recursos, composicion nutritiva y conservacion. Zaragoza: Acríbia, 1994. p.221-245.

MORAIS, C. Princípios da defumação de pescado. In: SIMPÖSIO E WORKSHOP: TECNOLOGIA DE SALGA E DEFUMAÇÃO DE PESCADO, 1994, Guarujá. Anais... Guarujá: Instituto de Tecnologia de Alimentos, 1994. p.21-28.

NUNES, M.L. Defumação. In: OGAWA, M.; MAIA, E.L. (Eds.) Manual de Pesca - ciência e tecnologia do pescado. São Paulo: Varela, 1999. v.1, p.300-306.

OGAWA, M. Alterações da carne de pescado por processamento e estocagem. In: OGAWA, M.; MAIA, E.L. (Eds.) Manual de pesca - ciência e tecnologia do pescado. São Paulo: Varela, 1999. v.1, p.221-249. 
RØRA, A.M.B.; KVALE, A.; MORKORE, T. et al. Process yield, color and sensory quality of smoked Atlantic salmon (Salmo salar) in relation to raw material characteristics. Food Research International, v.31, n.8, p.601-609, 1998.

RHEE, K.S.; BRATZLER, L.J. Benzo(a)pyrene in smoked meat products. Journal of Food Science, v.35, n.2, p.146-149, 1970 .

RIBEIRO, S.C.A. Secagem e defumação líquida de filé de peixe matrinchã (Brycon cephalus). Campinas: Universidade Estadual de Campinas, 2000. 101p. Dissertação (Mestrado em Engenharia de Alimentos) - Universidade Estadual de Campinas, 2000.

SHEARER, K.D. Factors affecting the proximate composition of cultured fishes with emphasis on salmonids. Aquaculture, v.199, p.63-88, 1994.

SIGURGISLADOTTIR, S.; SIGURGISLADOTTIR, M.S.; TORRISSEN, O. et al. Effects of different salting and smoking processes on the microstructure, the texture and yield of Atlantic salmon (Salmo solar) fillets. Food Research International, v.33, p.847-855, 2000.
SIMKO, P. Changes of benzo(a)pyrene contents in smoked fish during storage. Food Chemistry, v.40, n.3, p.293-300, 1991. SOUZA, M.L.R.; MACEDO-VIEGAS, E.M.; CARNEIRO, D.J. et al. Comparação dos processos de defumação a frio e a quente em filés de matrinxã (Brycon cephalus) sobre o rendimento e características organolépticas. In: AQÜICULTURA BRASIL, 11., 2000, Florianópolis. Anais... Florianópolis: Simbraq, 2000, não paginado, CD-ROM.

Recebido em: 13/05/02

Aceito em: 02/06/03 